\title{
Absence of impaired lymphocyte transformation to Klebsiella spp. in ankylosing spondylitis
}

\author{
T. DOUGLAS KINSELLA, CLAIRE LANTEIGNE, MARVIN J. FRITZLER, \\ AND RAYMOND M. LEWKONIA
}

From the Department of Medicine, Division of Rheumatology, University of Calgary, Calgary, Alberta, Canada.

SUMmARY We have evaluated claims that impaired peripheral blood lymphocyte (PBL) transformation can occur with Klebsiella spp. in patients with ankylosing spondylitis (AS). PBL of four AS patients were cultured in vitro with autogenous faecal klebsiella, as were the PBL of age ( \pm 3 years) and sex-matched pairs of 15-20 AS and normal controls cultured with heterogenous AS-derived klebsiella and control bacterial isolates. Three of four AS patients responded to their own isolates, and no significant differences were found between the matched pairs in response to heterogenous klebsiella isolates, including K21. Our studies did not show impaired PBL transformation with klebsiella in AS and therefore do not support claims of antigenic cross-reactivity between klebsiella and HLA-B27.

The aetiology and pathogenesis of ankylosing spondylitis (AS) remain unknown despite evidence which suggests an immunogenetic influence via the major histocompatability complex (MHC) because of the strong association of AS with HLA-B27. ${ }^{12}$ In relation to this, activated humoral immunity has been suggested by elevation of serum immunoglobulin (Ig) levels, including $\operatorname{IgA},{ }^{34}$ as well as serum complement (C) activation, and elevated levels of circulating immune complexes. ${ }^{4-6}$ Perhaps surprisingly the possible participation of cell-mediated immunity (CMI) in AS has been extremely controversial, ${ }^{7}$ though clarification of this has recently been suggested by studies which have implicated a role for organisms of the Klebsiella spp. ${ }^{8}{ }^{8}$ In view of these studies we wish to report our studies of in-vitro peripheral blood lymphocyte (PBL) transformation induced by isolates of Klebsiella spp. and control organisms from AS patients.

\section{Materials and methods}

\section{STUDY GROUPS}

Twenty AS patients ( 16 males and 4 females) were matched by sex and age ( \pm 3 years) with 20 normal controls. All AS patients had primary disease except

Accepted for publication 27 January 1984.

Correspondence to $\mathrm{Dr} \mathrm{T}$. D. Kinsella, University of Calgary, Health Sciences Centre, 3330 Hospital Dr NW, Calgary, Alberta, Canada T2N 4N1. two who developed inflammatory bowel disease during these studies two and five years after the onset of AS. Active disease, as defined previously by us, ${ }^{5}$ was present in $18 \mathrm{AS}$ patients whose disease duration was $1-34$ years (mean 10.7 years). Sixteen patients were withdrawn from all medication except acetaminophen at least 36 hours before study. Seventeen patients were positive $(+)$ and three negative (-) for HLA-B27.

Control subjects were selected to include 13 health care workers, since recent reports suggest that people who frequent health care facilities are liable to have increased, asymptomatic intestinal colonisation with klebsiella. ${ }^{10}{ }_{11}$ All controls were healthy, though two were HLA-B27 (+).

\section{B A CTERIA L ISOLATES}

Twenty-one stool cultures from 17 AS patients were propagated on trypticase soy broth (Difco) and yielded 5 klebsiella serotypes. The latter were kindly determined by Dr R. P. Rennie, of McMaster University, to represent two capsular strains of K7, and one each of $\mathrm{K} 21, \mathrm{~K} 33$, and $\mathrm{K} 68 .{ }^{12}$ Aliquots of washed isolates were propagated serially, as well as quick frozen, for use in in-vitro PBL transformation. Prior to the latter, viable isolates were fixed in $20 \%$ formalin, washed three times in Hanks's balanced salt solution (HBSS), recultured to ensure nonviability, and then resuspended in HBSS in appropriate concentrations. 
Control bacterial isolates consisted of a klebsiella pool (KP) of two urine and two stool strains, as well as a pool of Escherichia coli (EC) of two urine and two stool strains from non-AS donors. Serotyping of control isolates was not done.

\section{LYMPHOCYTE CULTURES}

PBL were recovered by density gradient separation (Lymphoprep-Nyegaard), washed, and resuspended in $10 \%$ human AB serum in Roswell Park Memorial Institute solution (RPMI) 1640 (Gibco). Isolated PBL were characterised as T-PBL by E rosettes and B-PBL by surface Ig staining. ${ }^{13}$ Mean values ( \pm SEM) derived from more than 150 normal control isolations were $73 \pm 9 \%$ T-PBL and $9 \pm 2 \%$ B-PBL: no significant differences were found for $T$ and B-PBL between AS patients and their matched controls in the present studies.

In 26 preliminary experiments microcultures containing $10^{5}$ PBL from normal subjects were established with $10^{4}, 10^{5}, 2 \times 10^{5}, 5 \times 10^{5}$, and $10^{6}$ bacterial isolates to determine optimal and suboptimal PBL: bacterial ratios. Culture conditions were otherwise identical to those subsequently employed (see below) and established $10^{5}$ and $10^{6}$ bacteria per $10^{5}$ PBL as suboptimal and optimal ratios respectively.

Triplicate experimental cultures containing $10 \%$ autologous plasma (AP) or AB serum in RPMI-1640 (Gibco), $10^{5} \mathrm{PBL}$, and $10^{5}$ and $10^{6}$ bacterial isolates were maintained in parallel for 132 hours in a humidified atmosphere of $5 \% \mathrm{CO}_{2}$ in air, pulsed with $0.5 \mu \mathrm{Ci}$ tritiated thymidine (Amersham Searle) in the final 18 hours, and then automatically harvested on filter discs (Skatron). Unstimulated controls, and mitogenic controls of phytohaemagglutinin (PHA-P Welcome, 0.025 and 0.05 $\mu \mathrm{g}$ / culture) and pokeweed mitogen (PWM Gibco, 1/10 and 1/40 stock dilutions in HBSS/culture) were established with each experiment. Radioactivity was calculated by liquid scintillation spectrometry (Beckman LS-3133T). Results are expressed as a stimulation index (SI) derived from the mean counts per minute (cpm) in stimulated (experimental) cultures divided by the mean cpm in unstimulated cultures.

Statistical calculations. Paired Wilcoxon rank sum and Student's $t$ tests, as appropriate, were used to compare the results of experimental and control groups by a TRS- 80 computer with custom programs. Twenty pairs of AS and control subjects were compared for the $\mathrm{KP}, \mathrm{K} 7(1)$, and EC isolates, and 18,17 , and 15 pairs for the $\mathrm{K} 7(2), \mathrm{K} 68$, and $\mathrm{K} 21$ isolates respectively.

\section{Results}

Transformation responses to autogenous klebsiella isolates. The results obtained when optimal doses of four klebsiella isolates from AS patients were cultured with their own PBL are shown in Table 1. Three of the four patients showed enhanced PBL transformation ( $\mathrm{SI}>5$ ) with their autogenous isolates in AP and/or AB serum. One patient (4) did not respond to his own $\mathrm{K} 21$ isolate or to the three other AS-derived isolates. All patients were HLAB27 (+), and all had active disease of at least moderate severity subjectively and objectively.

Under identical experimental conditions except for the use of suboptimal $\left(10^{5}\right)$ doses of autogenous isolates, two patients ( 1 and 4$)$ showed no mitogenic response $(\mathrm{SI}<1 \cdot 0)$. Patients 2 and 3 gave SI of $15 \cdot 0$ and 8.9 with suboptimal doses of their own isolates. Responses in $\mathrm{AB}$ serum with suboptimal doses of isolates were not determined.

Transformation responses to heterogenous klebsiella isolates. Maximum SI for the matched groups in response to optimal doses of heterogenous $\mathrm{KP}$, $\mathrm{K} 7(1), \mathrm{K} 7(2), \mathrm{K} 68$, and $\mathrm{K} 21$ in AP are shown in Fig. 1. No significant differences $(p>0.05)$ were found between the study groups for any klebsiella isolate, by Wilcoxon's rank sum test to compare the non-parametric results with $\mathrm{KP}, \mathrm{K} 7(1), \mathrm{K} 7(2)$ and $\mathrm{K} 68$, and Student's $t$ test for the parametric data of K21. The distribution of results with EC was virtually identical to that with $\mathrm{K} 21$ and was similarly not significantly different (data not shown).

Comparison of the SI of the matched study groups with suboptimal doses of each isolate in AP, and with optimal doses of all isolates in $A B$ serum, were not significantly different (data not shown). Although group responses in AP compared with $\mathrm{AB}$ were not significantly different, more than two-fold

Table 1 Peripheral blood lymphocyte transformation by autogenous klebsiella of AS patients

\begin{tabular}{|c|c|c|c|c|c|}
\hline Patient & $\begin{array}{l}\text { Serum } \\
\text { Supplement }\end{array}$ & $\begin{array}{l}\text { Stimula } \\
K 7(1)\end{array}$ & $\begin{array}{l}\text { on indes } \\
K 7(2)\end{array}$ & $\begin{array}{l}\text { with } \\
\text { K68 }\end{array}$ & $K 21^{\ddagger}$ \\
\hline 1 & $\begin{array}{l}\mathrm{AP} \\
\mathrm{AB}\end{array}$ & $\begin{array}{l}15 \cdot 3^{8} \\
240 \cdot 0\end{array}$ & $\begin{array}{l}\text { ND } \\
\text { ND }\end{array}$ & $\begin{array}{l}\text { ND } \\
\text { ND }\end{array}$ & $\begin{array}{l}\text { ND } \\
\text { ND }\end{array}$ \\
\hline 2 & $\begin{array}{l}\mathrm{AP} \\
\mathrm{AB}\end{array}$ & $\begin{array}{l}0 \cdot 4 \\
1 \cdot 1\end{array}$ & $\begin{array}{r}43 \cdot 2 \\
1 \cdot 2\end{array}$ & $\begin{array}{r}71 \cdot 1 \\
1 \cdot 2\end{array}$ & $\begin{array}{l}\text { ND } \\
\text { ND }\end{array}$ \\
\hline 3 & $\begin{array}{l}A P \\
A B\end{array}$ & $\begin{array}{r}16 \cdot 0 \\
4 \cdot 5\end{array}$ & $\begin{array}{r}3 \cdot 7 \\
13 \cdot 1\end{array}$ & $\begin{array}{l}0 \cdot 8 \\
7 \cdot 6\end{array}$ & $\begin{array}{l}\text { ND } \\
\text { ND }\end{array}$ \\
\hline 4 & $\begin{array}{l}\mathrm{AP} \\
\mathrm{AB}\end{array}$ & $\begin{array}{l}1.6 \\
1.7\end{array}$ & $\begin{array}{l}0 \cdot 5 \\
0 \cdot 2\end{array}$ & $\begin{array}{l}0 \cdot 3 \\
1 \cdot 3\end{array}$ & $\begin{array}{l}0.6 \\
1.8\end{array}$ \\
\hline
\end{tabular}

AP=autologous plasma and $\mathrm{AB}=$ human $\mathrm{AB}$ serum

${ }^{+}$Stimulation index $=$SI derived as per text.

${ }^{\ddagger}$ Designates capsular serotype: K7(1) and (2) represent identical serotypes but different biotypes.

${ }^{\$}$ SI expressed in italics are values obtained with autogenous klebsiella isolates; $\mathrm{ND}=$ not done. 


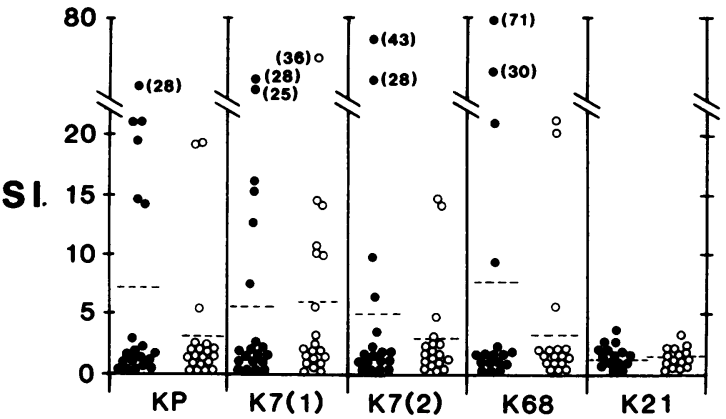

Fig. 1 Peripheral blood lymphocyte transformation by heterogenous klebsiella. Abbreviations correspond to those in Table $1 . \bigcirc=$ the SI for each AS patient, $\bigcirc=$ the SI for each matched normal control. - - - = group means.

changes were occasionally seen in the SI of some subjects' $\mathrm{PBL}$ in parallel cultures with $\mathrm{AP}$ and $\mathrm{AB}$ serum. For example, in response to isolate $K 7(1)$ the SI of four AS were higher in AP, whereas three were higher in $\mathrm{AB}$, and 13 were not significantly different.

No relationship was apparent between status for HLA-B27 and the magnitude or direction of PBL transformation to any isolate. In the AS group the same B27(-) patient hyperresponded to all isolates except $\mathrm{K} 21$, whereas all other AS hyperresponders were $\mathrm{B} 27(+)$. In the normal control group, all hyperresponders were B27(-) regardless of isolate tested.

No significant differences were found between the AS and normal control groups in their unstimulated and PBL transformation responses to all doses of PHA and PWM (data not shown).

\section{Discussion}

In contrast to some recent reports ${ }^{9}{ }^{14}$ we found no significant differences between AS and matched normal controls in their PBL transformation responses to several strains of klebsiella. Specifically, we found no impairment of AS-PBL transformation in response to AS-derived autogenous and heterogenous Klebsiella spp., to a pool of $E$. coli and to the primary T and B cell mitogens, PHA and PWM, respectively. Thus we would conclude that, in AS patients, CMI as measured by in-vitro PBL transformation is normal. Further, our data do not support claims that some form of antigenic crossreactivity exists between all $^{8}$ and some strains ${ }^{914}$ of Klebsiella spp. and HLA-B27.

The proponents of the klebsiella-B27 crossreactive association have reported impaired AS-
PBL transformation with certain strains of klebsiella, notably those which might carry the K43 and K21 capsular specificities. ${ }^{15} 16$ These observations, in conjunction with the results of microbiological, ${ }^{8}$ serological. ${ }^{1718}$ and lymphocytotoxicity studies ${ }^{9} 14$ ${ }^{16}$ have popularised the notion that antigenic crossreactivity between certain strains of klebsiella and HLA-B27, or a spatially related structure on the MHC, somehow induces AS. ${ }^{8914-18}$ In view of the profound biological implications of this hypothesis our studies have attempted to confirm the basic observations from which the hypothesis was apparently deduced. Some of our other studies, particularly those concerning lymphocytotoxicity, ${ }^{19}$ have been reported in preliminary form and, as with our present report, also do not substantiate a cross-reactive association between klebsiella and HLA-B27.

We would emphasise that our present studies were deliberately restricted to AS-derived faecal klebsiella, since it was assumed that these would more likely provide 'pathogenetic' strains. Indeed, of the five isolates which were serotyped one was identified as $\mathrm{K} 21$, reputedly a frequent participant in the putative cross-reaction with B27. ${ }^{15}{ }^{16}$ As with all klebsiella strains tested by us, however, AS and matched normal control PBL did not differ in their responses to these organisms, nor did three of four klebsiella donors show impaired responses to their own organisms. Thus the absence of impaired PBL transformation to AS-derived klebsiella in our studies, and in those of Enlow et al. ${ }^{20}$ does not support a role for cross-reactivity via these organisms and B27 in AS.

We have recently reviewed pertinent factors which might explain reported differences between those studies which support, and those which negate, a role for klebsiella in $\mathrm{AS}^{7}$ Accordingly, our studies were designed to evaluate the possible contradictory influences of control subjects' prior exposure to klebsiella, ${ }^{7}$ the inhibitory effects of anti-inflammatory medication, ${ }^{21}$ the modulating effects of age and sex on CMI, ${ }^{22}$ and the effect of serum supplements on in-vitro PBL transformation. ${ }^{23}$ We believe that we have reasonably accommodated all of the foregoing considerations in our present studies and yet failed to substantiate the affirmative reports by Seager et al. ${ }^{9}$ and Geczy et al. ${ }^{14} 15$

In conclusion, we and others ${ }^{1024}$ have not found persistent or specific intestinal colonisation by klebsiella serotypes, nor evidence of impaired in-vitro PBL transformation ${ }^{20}$ to klebsiella in AS patients. Although we accept the overwhelming epidemiological and clinical evidence of an as yet ill-defined association among HLA-B27, various Gram- 
negative bacteria, and spondylitic syndromes, ${ }^{7}$ we and others ${ }^{202526}$ have found no consistent evidence to implicate Klebsiella spp. in such an association.

We express our appreciation to Joan Miller and Betty Werschler for technical assistance. These studies were supported by a grant from the Canadian Arthritis Society (18-257-80) and were partly reported in Arthritis Rheum 1981; 24: 78 (abstr).

\section{References}

1 Brewerton D A, Caffery M, Hart F D, James D C O, Nicholls A, Sturrock R D. Ankylosing spondylitis and HL-A27. Lancet 1973; i: $904-7$.

2 Schlosstein L, Terasaki P J, Bluestone R, Pearson C M. High association of an HL-A antigen, W27, with ankylosing spondylitis. $N$ Engl $J$ Med 1973; 288: 704-6.

3 Kinsella T D, Espinoza L, Vasey F B. Serum complement and immunoglobulin levels in sporadic and familial ankylosing spondylitis. J Rheumatol 1975; 2: 308-13.

4 Sturrock R D, Barrett A J, Versey J, Reynolds P. Raised levels of complement inactivation products in ankylosing spondylitis. J Rheumatol 1974; 1: 428-31.

5 Rosenbaum J T, Theofilopoulos A M, McDevitt H O, Pereira A B, Carson D, Calin A. Presence of circulating immune complexes in Reiter's syndrome and ankylosing spondylitis. Clin Immunol Immunopathol 1981; 18: 291-7.

6 Kinsella T D, Lanteigne C, Lewkonia R M. Fritzler M J. Studies of circulating immune complexes in ankylosing spondylitis. Clin Invest Med 1982; 5: 223-30.

7 Kinsella T D, Fritzler M J, McNeil D J. Ankylosing spondylitis. A disease in search of microbes. $J$ Rheumatol 1983; 10: 2-4.

8 Ebringer R, Cooke D, Cawdell D R, Cowling P, Ebringer A. Ankylosing spondylitis: klebsiella and HL-A B27. Rheumatol Rehabil 1977: 16: 190-6.

9 Seager K, Bashir H V, Geczy A F, Edmonds J, de Vere-Tyndall A. Evidence for a specific B27-associated cell surface marker on lymphocytes of patients with ankylosing spondylitis. Nature 1979; 277: 68-70.

10 Warren R E, Brewerton D A. Faecal carriage of klebsiella by patients with ankylosing spondylitis and rheumatoid arthritis. Ann Rheum Dis 1980; 39: 37-44.

11 Ebringer R, Colthorpe D, Young A, Corbett M. Increased incidence of faecal Klebsiella pneumoniae in patients with HLA-B7 CREG antigen and men with rheumatoid arthritis. $\mathrm{Br}$ Med $J$ 1980; ii: 583-5.
12 Rennie R P, Duncan I B R. Combined biochemical and serological typing of clinical isolates of klebsiella. Appl Microbiol 1974; 28: 534-9.

13 Horwitz D A. Enumeration of human T, B, and L lymphocytes. In: Rose N R, Bigazzi P E, eds. Methods in immunodiagnosis. New York: Wiley, 1980: 1-13.

14 Geczy A F, Seager K. Bashir H, de Vere-Tyndall A, Edmonds $\mathrm{J}$. The role of klebsiella in the pathogenesis of ankylosing spondylitis. II. Evidence for a specific B-27 associated marker on the lymphocytes of patients with ankylosing spondylitis. $J$ Lab Clin Immunol 1980; 3: 23-8.

15 Geczy A F, Alexander K, Bashir H V, Edmonds J P. Characterization of a factor(s) present in klebsiella culture filtrates that specifically modifies an HLA-B27 associated cell-surface component. J Exp Med 1980; 152: 331s-40s.

16 Edmonds J, Macauley D, Ryndall A, et al. Lymphocytotoxicity of anti-klebsiella antisera in ankylosing spondylitis and related arthropathies. Arthritis Rheum 1981; 24: 1-7.

17 Welsh J, Avakian H, Cowling P, et al. Ankylosing spondylitis, HLA-B27 and klebsiella. I. Cross-reactivity studies with rabbit antisera. Br J Exp Pathol 1980; 61: 85-91.

18 Avakain H, Welsh J, Ebringer A, Entwistle C C. Ankylosing spondylitis, HLA-B27 and klebsiella. II. Cross-reactivity studies with human tissue typing sera. Br J Exp Pathol 1980; 61: 92-6.

19 Kinsella T D, Lanteigne C, Frizler M J, Lewkonia R M. Studies of lymphocytotoxicity by klebsiella antisera in ankylosing spondylitis. Arthritis Rheum 1982; 25: 563 (abstr).

20 Enlow R W, Bias W B. Bluestone R, Arnett F C. Human lymphocyte response to selected infectious agents in Reiter's syndrome and ankylosing spondylitis. Rheumatol Int 1982; 1: $171-5$.

21 Kuehl F A, Egan R W. Prostaglandins, arachidonic acid, and inflammation. Science 1980; 210: 978-84.

22 Cohn D A. High sensitivity to androgen as a contributing factor in sex differences in the immune response. Arthritis Rheum 1979; 22: 1218-33.

23 Vischer T L. Culture of mouse lymphoid cells in serum-free medium. J Immunol Methods 1972; 1: 199-202.

24 Eastmond C J, Willshaw H E, Burgess S E P. Shinebaum R, Cooke E M, Wright V. Frequency of faecal Klebsiella aerogenes in patients with ankylosing spondylitis and controls with respect to individual features of the disease. Ann Rheum Dis 1980; 39: 118-23.

25 Archer J R. Search for cross-reactivity between HLA-B27 and Klebsiella pneumoniae. Ann Rheum Dis 1981; 40: 400-3.

26 Beaulieu A D, Rousseau F, Israel-Assayag E, Roy R. Klebsiella related antigens in ankylosing spondylitis. $J$ Rheumatol 1983; 10: 102-5. 